\title{
Sauna-induced body mass loss in physically inactive young women and men
}

\author{
Robert Podstawski ${ }^{1}$, Tomasz Boraczyński², Michał Boraczyński², Dariusz Choszcz ${ }^{3}$, \\ Stefan Mańkowski ${ }^{3}$ Piotr Markowski ${ }^{3}$
}

${ }^{1}$ Department of Physical Education and Sport, University of Warmia and Mazury, Olsztyn, Poland; ${ }^{2}$ Józef Rusiecki Olsztyn University College, Department of Physical Education, Olsztyn, Poland; ${ }^{3}$ Department of Heavy Duty Machines and Research Methodology, Faculty of Technical Sciences, University of Warmia and Mazury, Olsztyn, Poland

\section{Summary}

Study aim: The aim of this study was to evaluate the relationship between basic somatic features (body mass and height) and body mass loss in physically inactive young women and men exposed to thermal stress in a dry sauna.

Materials and methods: The research was conducted in 2015 on 685 first-year full-time students (333 women, 352 men), aged 19-20 years old. Nude body mass was measured after the students dried off before and after using the sauna.

Results: An analysis of regression equations indicated that an increase in the body mass of women and men leads to a significant increase in sauna-induced body mass loss. On the other hand, body mass loss decreased with an increase in height in women and men, but to a smaller extent. From among the tested somatic features, body height and body mass, body mass had a decisive influence on body mass loss. Body height had a minimal and statistically non-significant impact on body mass loss. Conclusions: The results of this study indicate that heavier individuals have an increased risk of dehydration and hyperthermia. Therefore, they should pay close attention to replenishing fluids lost in the sauna. The determination of body mass loss values after a visit to a dry sauna has practical significance because it supports the estimation of the fluid volume required for the maintenance of correct water balance.

Key words: Dry sauna - Thermal stress - Body mass loss - Somatic features - Physically inactive people

\section{Introduction}

Sauna bathing, a well-known form of whole-body heating, is well-tolerated by most healthy individuals, both young and old between childhood and old age $[10,16,18]$. Repeated sauna bathing influences endogenous regulatory mechanisms, mainly acute and transient cardiovascular and hormonal changes, by maintaining a balance between fluid composition and the distribution of circulating blood [1]. Uncontrolled sauna bathing poses various health risks, such as severe dehydration, heat exhaustion, stroke or burns $[9,22,31]$.

In most dry sauna rooms, the temperature is maintained between 80 and $90^{\circ} \mathrm{C}$, and sometimes even above $100^{\circ} \mathrm{C}[20,31]$. Temperatures between of 80 and $90^{\circ} \mathrm{C}$ at face level are considered optimal for most people [23]. The composition of the human body changes under such thermal conditions. Water is one of the basic components of the human body ( $48 \pm 6 \%$ in women; $58 \pm 8 \%$ water in men) [44]. The body of a typical man weighing $75 \mathrm{~kg}$ contains approximately $45 \mathrm{~L}$ of water (approximately $60 \%$ of his body mass) [37]. The water and electrolyte balance is critical for the function of all organs and for the maintenance of health in general $[24,36]$. Total body water percentage normally remains relatively constant [36]. Every fluid compartment in the body contains electrolytes whose concentrations and composition are critical for fluid movement between intracellular and extracellular compartments and for the maintenance of membrane electrochemical potentials [37]. Dehydration can be induced in a sauna (passive dehydration) [40]. Sauna-induced dehydration leads to hyperthermia due to enhanced sweating [47]. The loss of bodily fluids corresponding to $1 \%$ body mass can reduce endurance by 4 to $6 \%$, strength by 4 to $7 \%$ and coordination and concentration by $8 \%$ [30]. Sweat evaporation and 
blood circulation in the skin are the main cooling mechanisms in the body [9]. Uncontrolled sweating leads to the loss of body mass $(0.5-1.0 \mathrm{~kg})$ [22]. Sauna-induced body mass loss (BML) involves mainly the loss of body water, but electrolytes, in particular sodium and chloride, are also lost in various amounts depending on the sweat rate and sweat composition [41]. Severe sweat-induced dehydration can impair exercise performance and the performance of tasks requiring cognition and skill $[25,30]$. Thus, the critical issue in sauna bathing is to minimize dehydration by matching fluid intake with sweat loss.

In the human body, dehydration leads to a decrease in body mass [33]. According to the literature, the loss of $1 \mathrm{~kg}$ of body mass corresponds to approximately $1 \mathrm{~L}$ of bodily fluids lost through sweating [26, 38]. Measurements of sauna-induced body mass loss can be used to calculate the volume of water that should be consumed to compensate for that loss. The physiological processes connected with thermal stress induced by heat exposure in a sauna have been studied and characterized by many authors, but the precise mechanisms behind these phenomena still remain insufficiently explained [10, 22].

In view of the documented risks associated with excessive thermal stress in a sauna, BML control is a useful method of preventing dehydration, hyperthermia and the resulting health problems. Dehydration combined with hyperthermia has more severe consequences than dehydration or hyperthermia alone [3]. Significant differences in anthropometric measures and body composition are noted between healthy sedentary women and men [19]. It remains unknown whether BML can be reliably estimated in view of considerable sex-related and individual differences in body measurements and body composition.

Therefore, the aim of this study was to evaluate the relationship between basic somatic features (independent variables: body mass and body height) and body mass loss (dependent variable) in physically inactive young women and men exposed to thermal stress in a dry sauna.

\section{Materials and methods}

\section{Ethical approval}

The research was carried out with the prior consent of the Ethical Committee of the University of Warmia and Mazury in Olsztyn (UWM), Poland. The study was performed on student volunteers who signed an informed consent statement.

\section{Participants}

The research was conducted in 2015 on 685 first-year full-time students (333 women, 352 men), aged 19-20 years old, who were enrolled at UWM. Every volunteer visited a dry sauna during obligatory physical education
(PE) classes at the university. The analysed subjects, both women and men, were residents of villages, towns and cities (population $<40,000$ ) in the region of Warmia and Mazury in Poland. The participants attended only mandatory PE classes (90 minutes per week) and did not participate in any other physical activities. The students' physical activity levels were evaluated using the International Physical Activity Questionnaire (IPAQ). An analysis of physical activity levels based on the IPAQ revealed that none of the participants were sufficiently active and that their physical activity levels were below 600 MET. The examined women and men were characterized by low levels of physical activity, and they were classified as being insufficiently active. According to the IPAQ, people who are insufficiently active represent the lowest level of physical activity and do not meet the criteria for minimally active and highly active categories [6]. The IPAQ was used to select female and male students who would constitute a homogenous group of respondents with regard to their physical activity.

The participants did not visit a sauna for a least 12 months before the study. None of the examined women were menstruating during the study. The following formula was used to determine whether the number of participants constituted a representative sample in the trial (1):

$$
\mathrm{n}=\frac{\mu_{\alpha}^{2} \cdot \hat{s}^{2}}{d^{2}}
$$

where: $d$ - maximum (acceptable) error of estimation, $s$-standard deviation, $\mu_{\alpha}-$ value from the normal distribution table $N(0.1)$ at the acceptable confidence coefficient of $1-\alpha\left(\mu_{\alpha}=1.96\right)$. At the assumed level of significance $(\alpha=0.05)$, it was presumed that the error of estimation of the average did not exceed $2 \%$ [34]. The size of a representative sample, calculated from formula (1) at $2 \%$ error of estimation, was 221 women and 198 men, and it was smaller than the studied group (326 females, 348 males). Consequently, the trial can be considered homogenous and representative of UWM students in the age group of 19-20 years old.

\section{Instruments and procedures}

The participants received comprehensive information about the trial before the study. Body height was measured to the nearest $0.1 \mathrm{~mm}$, and body mass was measured to the nearest $0.1 \mathrm{~kg}$ with calibrated WB-150 medical scales with a stadiometer (ZPU Tryb-Wag, Poland). Body mass $(\mathrm{BM})$ and body height $(\mathrm{BH})$ were the independent variables (X), and BML was the dependent variable (Y). Nude $\mathrm{BM}$ was measured after the students dried off before and after using the sauna. The subjects were placed in supine position in a dry sauna (temperature: $90^{\circ} \mathrm{C}$; relative humidity: 35\%) for two sessions of 10 minutes each with a 5-minute break in between to cool the body in a paddling 
pool (pool width: $100 \mathrm{~cm}$; pool depth: $130 \mathrm{~cm}$; water temperature: $+10^{\circ} \mathrm{C}$ ). The subjects were instructed to drink at least $1 \mathrm{~L}$ of water on the day before the test and $0.5 \mathrm{~L}$ of water 2 hours before the test. Following that, the participants did not consume any foods or fluids until after the final body measurements were taken.

\section{Statistical analysis}

Measurement results were processed statistically in the Statistica PL v. 10 application with the use of descriptive statistics and advanced models to calculate the basic indicators describing the location and distribution of the analysed factors. The influence of body mass and body height on body mass loss in a sauna was determined by curvilinear regression analysis with the stepwise method. The results of the regression analysis were presented in $2 \mathrm{D}$ and 3D figures [34].

\section{Results}

The basic anthropometric parameters and sauna-induced body mass loss (BML) in women and men are presented in Table 1.

Body mass and body height values were evaluated based on score tables (T scale) for the general population of Polish women and men [7]. The tested women and men were characterized by average body mass and body height relative to the general population of the corresponding age. The average scores in the evaluated population were determined in the range of $49-53$ points (women: $\mathrm{BM}=51$ points, $\mathrm{BH}=49$ points; men: $\mathrm{BM}=53$ points, $\mathrm{BH}=52$ points).

In the dry sauna, men lost more bodily fluids (BML) $(p=0.0105)$ than women. The differences between extreme values of body mass $(42.4 \mathrm{~kg}$ in women, $70.0 \mathrm{~kg}$ in men) and body height ( $37.0 \mathrm{~cm}$ in women, $42.0 \mathrm{~cm}$ in men) were very high in both women and men. The coefficient of variation in body mass $(\mathrm{CV}=16.35 \%$ for women, $17.98 \%$ for men) was approximately four times higher than the coefficient of variation in body height $(\mathrm{CV}=4.33 \%$ for women, $4.17 \%$ for men). Relatively low variation in body height and considerably higher variation in body mass significantly contributed to disproportionately higher variation in sauna-induced body mass loss (BML) - the CV reached $46.97 \%$ in women and $46.44 \%$ in men. These results supported the formulation of the hypothesis that a relatively small change in the analysed variables (body mass and body height) significantly influences sauna-induced body mass loss in both women and men. A series of statistical analyses were conducted to verify the above hypothesis.

The null hypothesis $\left(\mathrm{H}_{0}\right)$ claiming that the analysed variables $(\mathrm{BM}$ and $\mathrm{BH})$ did not influence the average BML values in women $\left(\mathrm{BML}_{1}\right)$ and men $\left(\mathrm{BML}_{2}\right)$ was rejected based on the results of the statistical analyses. The hypotheses postulating the existence of regression coefficients for women and men were verified.

The F-value was determined at $\mathrm{F}=364.3$ for women and $\mathrm{F}=510.6$ for men, with the probability that the calculated test value for women and men will be exceeded at $\mathrm{p}(\mathrm{F})<0.001$; a significance level of $\alpha=0.05$, multiple correlation coefficient of $r=0.832$ for women and $\mathrm{r}=0.865$ for men and residual standard deviation of 0.0954 for women and 0.1166 for men were also determined. Since $\mathrm{p}(\mathrm{F})<\alpha, \mathrm{H}_{0}$ (regression coefficients equal zero) was rejected on behalf of the alternative hypothesis $\mathrm{H}_{1}$ (not all regression coefficients equal zero). Regression equations describing the influence of selected independent variables $(\mathrm{BM}$ and $\mathrm{BH})$ on the dependent variable (BML) were derived:

for women: $\mathrm{BML}_{1}=0.1996+0.0159 \mathrm{BM}_{1}-0.0047 \mathrm{BH}_{1}(2)$ for men: $\mathrm{BML}_{2}=-0.4701+0.0149 \mathrm{BM}_{2}-0.0009 \mathrm{BH}_{2}$

Table 1. Basic metrics in women and men - body mass (BM), body height (BH) and sauna-induced body mass loss (BML)

\begin{tabular}{llcccccccc}
\hline \multirow{2}{*}{ No. } & Parameter & \multicolumn{4}{c}{ Women } & \multicolumn{4}{c}{ Men } \\
\cline { 2 - 9 } & BM $[\mathrm{kg}]$ & BH [cm] & BML $[\mathrm{kg}]$ & BML $[\%]$ & BM $[\mathrm{kg}]$ & BH [cm] & BML $[\mathrm{kg}]$ & BML [\%] \\
\hline 1. & Maximum & 85.80 & 184.0 & 1.20 & 1.44 & 121.00 & 204.0 & 1.30 & 1.23 \\
2. & Minimum & 43.40 & 147.0 & 0.10 & 0.22 & 51.00 & 162.0 & 0.10 & 0.19 \\
3. & Mean & 59.10 & 164.98 & 0.37 & 0.59 & 75.98 & 180.73 & 0.50 & 0.63 \\
4. & Median & 56.45 & 165.0 & 0.30 & 0.57 & 74.50 & 180.0 & 0.40 & 0.62 \\
5. & Standard deviation & 9.663 & 7.148 & 0.171 & 0.19 & 13.662 & 7.528 & 0.231 & 0.19 \\
6. & Coefficient of & \multirow{2}{*}{16.35} & 4.33 & 46.97 & 31.68 & 17.98 & 4.17 & 46.44 & 30.94 \\
\hline
\end{tabular}

Calculated $U$ test value -2.5576 ; Probability of exceeding the calculated $p(U)$ value $=0.0105$; Significance level $-\alpha=0.05 ; p(U)<\alpha-$ statistically significant differences 

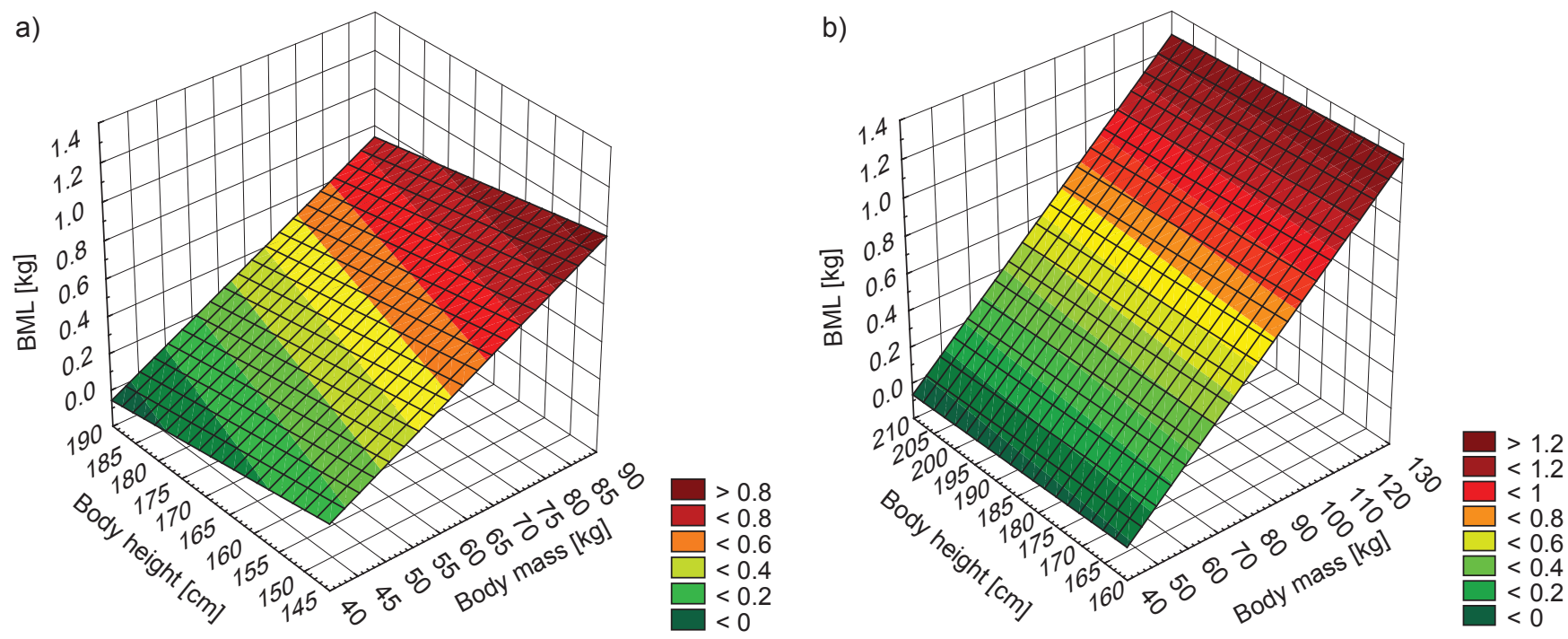

Fig. 1. Sauna-induced body mass loss (BML) subject to body mass (BM) and body height (BH) in women (a) and men (b)

These correlations are presented graphically in Figures $1 \mathrm{a}$ and $1 \mathrm{~b}$.

An analysis of equations (2) and (3) and their graphical interpretations (Fig. 1a and 1b) indicates that an increase in the body mass of female and male subjects leads to a significant increase in sauna-induced body mass loss (BML). $\mathrm{BML}_{1}$ decreased with an increase in female height $\left(\mathrm{BH}_{1}\right)$. This trend was also noted in men, but to a smaller extent. Equations (2) and (3) can be used to stimulate BML under conditions described in this experiment (two 10-minute

Table 2. Sauna-induced body mass loss (BML) subject to body mass $(\mathrm{BM})$ in women $(\mathrm{BH}=165 \mathrm{~cm})$ and men $(\mathrm{BH}=181 \mathrm{~cm})$. The simulation was based on equations (2) and (3)

\begin{tabular}{lccc}
\hline Gender & BM $[\mathrm{kg}]$ & BML $[\mathrm{kg}]$ & BML $[\%]$ \\
\hline \multirow{4}{*}{ Women } & 49 & 0.203 & 0.415 \\
& 54 & 0.282 & 0.524 \\
& 59 & 0.362 & 0.614 \\
& 64 & 0.441 & 0.690 \\
& 69 & 0.521 & 0.755 \\
\multirow{4}{*}{ Men } & 65 & 0.335 & 0.516 \\
& 71 & 0.424 & 0.598 \\
& 76 & 0.499 & 0.657 \\
& 81 & 0.573 & 0.709 \\
& 86 & 0.648 & 0.754 \\
\hline
\end{tabular}

visits to a sauna at a temperature of $90^{\circ} \mathrm{C}$ and relative humidity of 35\%). The results of BML simulations based on body mass and body height data are presented in Tables 2 and 3 .

The results of the simulation presented in Table 2 indicate that in both women and men, an increase in body mass (on the assumption that body height remains constant) leads to an increase in BML values in both absolute $(\mathrm{kg})$ and relative (\%) terms. With an increase in BML [\%], the difference in the value of this indicator levelled out between female

Table 3. Sauna-induced body mass loss (BML) subject to body height $(\mathrm{BH})$ in women $(\mathrm{BM}=59 \mathrm{~kg})$ and men $(\mathrm{BM}=76 \mathrm{~kg})$. The simulation was based on equations (2) and (3)

\begin{tabular}{lccc}
\hline Gender & BH $[\mathrm{cm}]$ & BML $[\mathrm{kg}]$ & BML [\%] \\
\hline \multirow{4}{*}{ Women } & 155 & 0.409 & 0.264 \\
& 160 & 0.385 & 0.241 \\
& 165 & 0.362 & 0.220 \\
& 170 & 0.338 & 0.199 \\
& 175 & 0.315 & 0.180 \\
Men & 171 & 0.508 & 0.297 \\
& 176 & 0.503 & 0.286 \\
& 181 & 0.499 & 0.276 \\
& 186 & 0.494 & 0.266 \\
& 191 & 0.490 & 0.257 \\
\hline
\end{tabular}


and male respondents. Practically no differences in relative BML [\%] were observed between groups characterized by the highest body mass. In the group of the heaviest women, BML $[\mathrm{kg}$ ] was more than $150 \%$ higher than in the group of the lightest women. The difference in BML between the lightest and the heaviest men was clearly smaller (below $100 \%)$. A comparison of the lightest men and women revealed a difference in BML of more than $50 \%$, whereas the difference between the heaviest groups of respondents was estimated at only $20 \%$.

The results of the simulation presented in Table 3 indicate that unlike in the above comparison, an increase in body height (on the assumption that body mass remains constant) was accompanied by a minimal decrease in BML $[\mathrm{kg}]$ in women, but no changes in BML in men. The above results suggest that BML is largely determined by body mass.

The stepwise method was used to simplify polynomial terms (equations 2 and 3). BML equations were derived based on body mass values in women and men. The resulting correlations were presented graphically in Figures $2 \mathrm{a}$ and $2 \mathrm{~b}$.

In theory, BML for women and men can be estimated based on body mass values with the use of the equations below:

for women: $\quad \mathrm{BML}_{1}=-0.4878+0.0144 \mathrm{BM}_{1}$ for men: $\quad \mathrm{BML}_{2}=-0.6128+0.0146 \mathrm{BM}_{2}$

The percentage of the explained variation is $66.15 \%$ for women (equation 4) and $74.69 \%$ for men (equation 5). Multiple correlation coefficients for equations (4) and (5) are very high at 0.813 for women and 0.864 for men. Residual standard deviation reached 0.1001 for women and 0.1165 for men. High correlation coefficients and relatively low residual standard deviations indicate that the derived

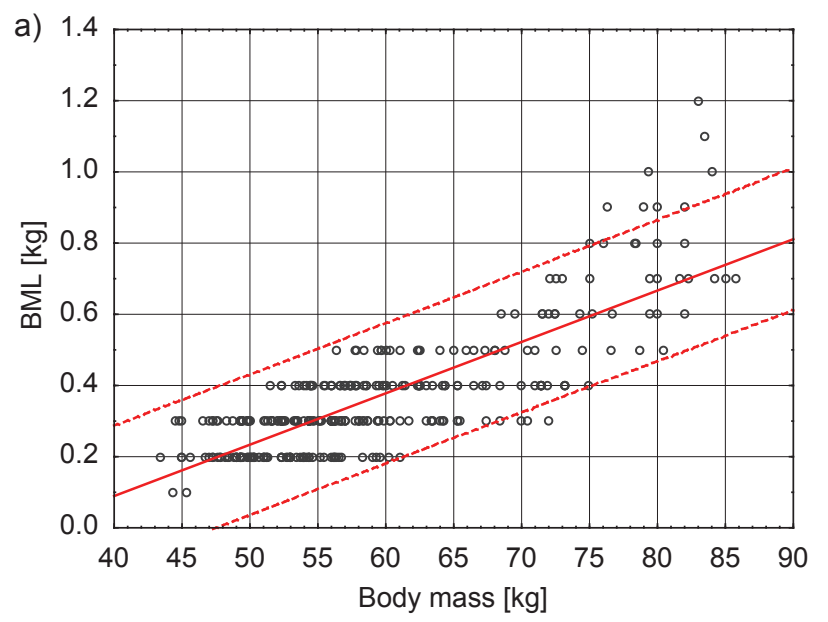

models (equations) fit empirical data well. Equations (4) and (5) can be used to predict BML values in women and men with high accuracy.

The results of BML simulations based on body mass values in women and men are presented in Table 4.

The results of the simulation presented in Table 4 indicate that BML increases with a rise in body mass values in both women and men. An increase in body mass by one kilogram increased BML values by $0.0144 \mathrm{~kg}$ in women and $0.0146 \mathrm{~kg}$ in men on average. The difference in BML values between women and men decreased with an increase in body mass. Men were characterized by higher BML than women in each body mass category, but in similar weight groups, men tended to lose less body mass than women.

Table 4. Sauna-induced body mass loss (BML). The simulation was based on equations (4) and (5)

\begin{tabular}{lccc}
\hline Gender & BM $[\mathrm{kg}]$ & BML $[\mathrm{kg}]$ & BML [\%] \\
\hline \multirow{4}{*}{ Women } & 49 & 0.217 & 0.444 \\
& 54 & 0.289 & 0.537 \\
& 59 & 0.361 & 0.613 \\
& 64 & 0.433 & 0.678 \\
& 69 & 0.505 & 0.733 \\
& 65 & 0.336 & 0.517 \\
& 71 & 0.423 & 0.597 \\
& 76 & 0.496 & 0.654 \\
& 81 & 0.569 & 0.703 \\
& 86 & 0.642 & 0.747 \\
\hline
\end{tabular}

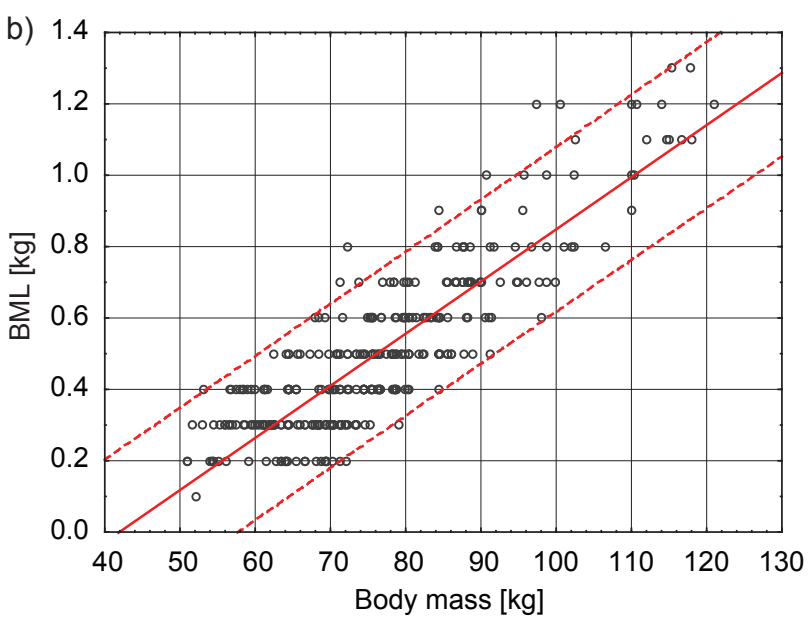

Fig. 2. Sauna-induced body mass loss (BML) subject to body mass (BM) in women (a) and men (b). The results are presented in the confidence interval of 0.95 (dotted lines) 

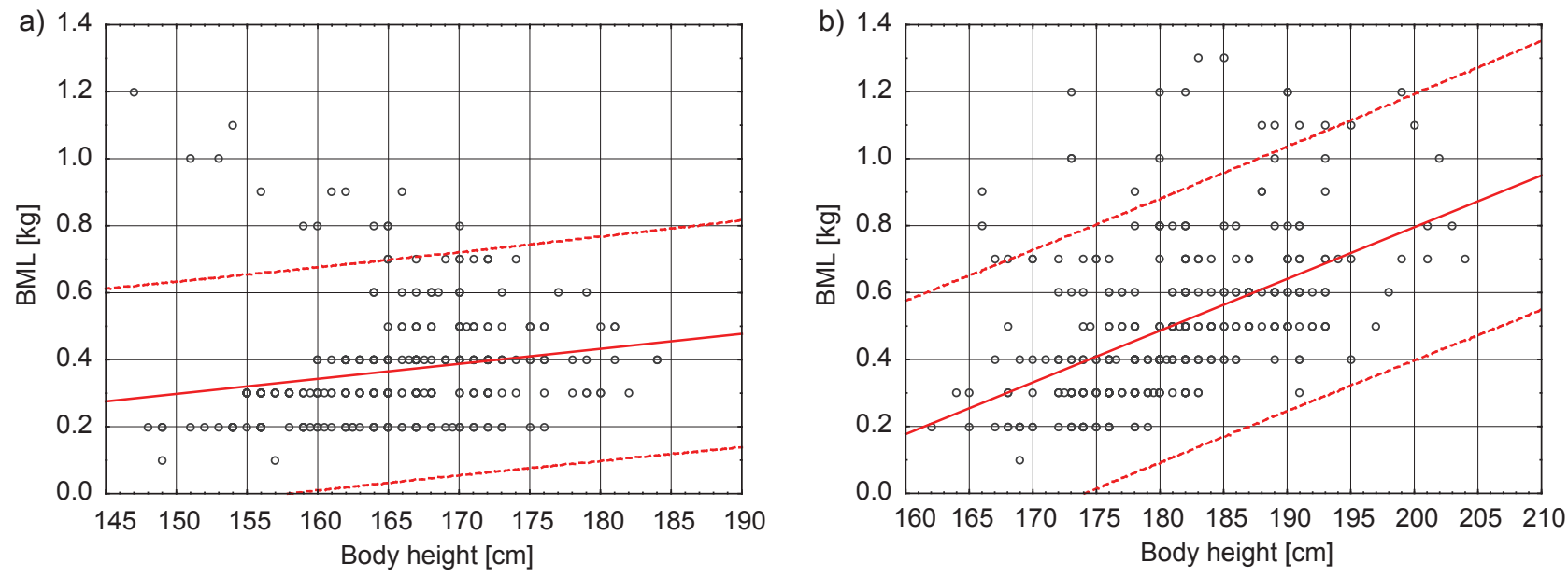

Fig. 3. Sauna-induced body mass loss (BML) subject to body height (BH) in women (a) and men (b). The results are presented in the confidence interval of 0.95 (dotted lines)

Body height did not exert a significant influence on $\mathrm{BML}$ in women or men. The derived equations explained $3.5 \%$ of variation in women and $25 \%$ of variation in men. The results are presented graphically in Figures $3 \mathrm{a}$ and $3 b$.

The results of statistical analyses suggest that from among the tested variables, body mass is the key determinant of BML in both women and men. Body height had a minimal and statistically non-significant influence on BML. The error generated by equations with one variable (BM, equations 4 and 5) and two variables (BM and $\mathrm{BH}$, equations 2 and 3) ranged from $0.1 \%$ to $0.6 \%$ BML. It is recommended that equations with one variable (BM, equations 4 and 5) are used because they are easier to interpret than equations with two independent variables (BM and $\mathrm{BH}$, equations 2 and 3) and fit empirical data similarly well.

\section{Discussion}

The main objective of this study was to evaluate the relationship between basic somatic features (body mass and body height) and body mass loss (BML) in physically inactive young women and men exposed to thermal stress in a dry sauna. As was previously mentioned, sweating and water evaporation from the skin are the most effective mechanisms of heat elimination in humans. Sauna bathing has been shown to affect the fluid, electrolyte and acidbase balance resulting from sweating and thirst [33]. During sauna bathing, sweating begins quickly and reaches peak levels after approximately 15 minutes, with an average total secretion of $0.5 \mathrm{~kg}$ [15]. The magnitude of core temperature elevation ranges from 0.1 to $0.25^{\circ} \mathrm{C}$ for every percent of BML [28, 39].

According to Sawka and Montain [37], in situations of prolonged high sweat loss, body water loss (BWL) in adults can reach $2-8 \%$. Body water loss of $2 \%$ can reduce work capacity by $20 \%$. Marked dehydration (5\% BWL) reduces threshold and slope responses for sweating $[29,39]$. Dehydration in excess of $5 \%$ BWL can have serious health implications, and BWL higher than $8-10 \%$ has lethal consequences [35].

One of the first studies concerning the effects of sweating on fluid balance was carried out by Kozłowski and Saltin [21]. In their study, sweating-induced dehydration was analysed in six healthy males who were exposed to a temperature of $80^{\circ} \mathrm{C}$ during a 2.5 -hour visit to a sauna. The average decrease in body mass was $3.1 \mathrm{~kg}(4.1 \%)$.

In several studies, the average body water loss during a standard sauna visit was estimated at $400-600 \mathrm{~g}$ $[12,14]$. Similar BWL values were observed by Pilch et al. [33]. The authors investigated changes in BML and various physiological and biochemical indicators in 10 healthy female subjects (aged 19-21 years old) who visited a Finnish sauna every other day for a total of seven visits (temperature: $80.1^{\circ} \mathrm{C}$; relative humidity: $26.6 \%$; duration: 30 minutes). On average, the subjects' body mass decreased by $550 \mathrm{~g}$ after the first visit $(0.94 \%$ decrease in initial body mass) and by $560 \mathrm{~g}$ after the seventh, final visit ( $0.96 \%$ decrease in initial body mass).

In a study by Coles et al. [5], 10 male subjects attended six 15-minute sessions in a dry sauna (at a temperature of $48.9^{\circ} \mathrm{C}$ ) with 5 -minute breaks between sessions. The study involved two different procedures (euhydration trial vs. dehydration trial). No fluids were ingested at any time during the dehydration procedure. The euhydration procedure was identical to the dehydration procedure, with the exception that during each 5-minute break, the subjects were instructed to drink a volume of water equivalent to the body mass lost during the previous 15 -minute sauna session. The subjects' BML was $0.33 \pm 0.19 \mathrm{~kg}$ (euhydration trial) and $1.99 \pm 0.35 \mathrm{~kg}$ (dehydration trial). Euhydration 
resulted in $0.4 \%$ BML and dehydration resulted in $2.3 \%$ BML. Westerterp-Plantenga et al. [46] reported significant differences $(p<0.001)$ in the BML values $(-1.82 \mathrm{~kg}$; in the range of -1.53 to $-2.04 \mathrm{~kg} ; 3.0 \pm 0.5 \%$ ) of 30 nonobese $(\mathrm{BMI}=22.8 \pm 1.6)$ and obese $(\mathrm{BMI}=28.5 \pm 1.9)$ subjects who attended three 20-minute sauna sessions at a temperature of $80^{\circ} \mathrm{C}$. In a study by Thomas et al. [43], the mean BML (normalized to body mass \%) of 12 healthy adults after a 30-minute sauna visit was $0.91 \pm 0.34 \%$ (range $0.33-1.4 \%$ ).

In our study, where a similar procedure was applied, male subjects lost $0.50 \mathrm{~kg}(0.63 \%)$, whereas female subjects lost $0.37 \mathrm{~kg}(0.60 \%)$ on average. In light of the cited results, the BML values reported in our study do not seem to pose a considerable health risk. Due to the considerable differences in body measurements and body composition between females and males, the results of our study were analysed to determine whether sex significantly influences BML values.

Numerous studies analysing differences between the sexes demonstrated a much higher increase in whole-body sweat rate in men than in women as the result of adaptation to humid heat $[2,4,8,45]$. Avellini et al. [2] observed a significantly higher increase in the whole-body sweat rate in men than in women (35\% vs. $15 \%)$ after 10 days of adaptation to humid heat. Mehnert et al. [27] reported highly significant sex-related differences in sweat rates. The differences remained statistically significant even when women and men were matched for body surface area or surface-to-mass ratio. Similar differences were observed in resting and exercising subjects in other studies $[11,13]$.

In our study, the average body mass loss was $130 \mathrm{~g}$ $(26 \%)$ higher in men than in women. A statistically significant difference $(p=0.0105)$ in BML $[\%]$ was observed between the sexes $(0.60 \%$ and $0.63 \%$, respectively). The average BML $[\mathrm{kg}]$ in our research was similar to that reported in men in other studies [23, 33, 42], but lower than that noted by Pilch et al. [32]. The fact that women lost less body mass $[\mathrm{kg}]$ could be attributed to the fact that females are generally characterized by lower levels of total body water ( $48 \pm 6 \%$ ) [44] and a higher content of adipose tissue, which reduces sweating, evaporation and BML $[\mathrm{kg}][12,14]$. Women also require a greater increase in body temperature before they begin to sweat. They do not sweat as much as men, and they maintain a steady body temperature less effectively than men [17]. The above observations were confirmed in our study, in which men lost more body mass than women. The presented simulations revealed that men with a body mass similar to that of women were characterized by lower BML in $\mathrm{kg}$ and $\%$. The above can probably be attributed to differences in body surface between the sexes, which influences heat loss through radiation [26]. Men whose body mass is similar to that of women are characterized by less body fat and greater body surface. Therefore, our results could also suggest that body fat is a significant determinant of BML. Women with more body fat than men probably lose more body mass to maintain thermal homeostasis (relatively constant body temperature). Further work is needed to determine the correlations between body measurements and body composition vs. BML.

From a practical point of view, it is important to determine which of the two basic somatic features, body height or body mass, has a greater influence on BML. Our findings have revealed that the correlation between body mass and BML is directly proportional and statistically significant. The relationship between body height and BML is inversely proportional and statistically non-significant, which implies that BML decreases with an increase in $\mathrm{BH}$ (when body mass is stable).

The regression equations derived in our study can be used to determine the influence of the analysed somatic features on BML values in young women and men exposed to thermal stress in a dry sauna. The derived equations support highly accurate estimations of body mass loss in a sauna. From among the two independent variables (somatic features) analysed in this study, body mass had a decisive impact on BML values in both women and men. On average, a body mass increase of $1 \mathrm{~kg}$ leads to a BML of $0.0144 \mathrm{~kg}$ in women and $0.0146 \mathrm{~kg}$ in men. Average BML values in men were approximately $30 \%$ higher than in women. In groups of female and male respondents characterized by a similar body mass, BML values were approximately $16-23 \%$ higher in women than in men. The noted difference was reduced with an increase in body mass.

\section{Conclusions}

The results of our study indicate that physiological responses to thermal stress in a dry sauna differed subject to gender, body mass and body height. From among the tested somatic features, body mass had a decisive influence on BML. Men whose body mass was similar to that of women were characterized by lower BML, which indicates that the physiological effort required to maintain constant body temperature is lower in men. The observed differences could be attributed to lower body fat and greater body surface area in men than in women. In both men and women, an increase in body mass was accompanied by a rapid increase in BML values [\%], which suggests that body fat significantly influences BML. Body height had a minimal and statistically non-significant impact on BML. Our findings suggest that BML can be estimated based on subjects' initial body mass. A directly proportional correlation between body mass and BML 
indicates that regardless of gender, heavier participants, in particular those with higher body fat, are at a greater risk of dehydration and hyperthermia; therefore, they should pay close attention to replenishing fluids lost in a sauna or shorten their visits to saunas. The determination of BML values after a visit to a dry sauna has practical significance because it supports the estimation of the fluid volume required for the maintenance of correct water balance. Thermoregulation involves complex mechanisms; therefore, future research should involve a higher number of variables describing somatic features, height/weight indicators and body composition.

\section{References}

1. Ahonen E., U. Nousiainen (1988) The sauna and body fluid balance. Ann. Clin. Res., 20: 257-261.

2. Avellini B., E. Kamon, J.T. Krajewski (1980) Physiological responses of physically fit men and women to acclimation to humid heat. J. Appl. Physiol., 49: 254-261.

3. Barr S.I. (1999) Effects of dehydration on exercise performance.Can. J. Appl. Physiol., 24(2): 164-172.

4. Buono M.J., S.M. Leichliter, J.H. Heaney (2010) Peripheral sweat gland function, but not whole-body sweat rate, increases in women following humid heat acclimation. J. Therm. Biol., 35: 134-137.

5. Coles M.G., A. Hernández, T.R. Anderson (2006) Effect of thermal-induced dehydration on vo2 recovery time and heart rate response. J. Exerc. Sci. Fit., 4(1): 36-41.

6. Craig C.L., A.L. Marshall, M. Sjöström M,A.E. Bauman, M.L. Booth, B.E. Ainsworth, M. Patt, U. Eukelund, A. Yngve, J.F. Sallis, P. Oja (2003) International physical activity questionnaire: 12-country reliability and validity. Med. Sci. Sports. Exerc., 35(8): 1381-1395.

7. Dobosz J. (2012) Tabele punktacyjne wysokości i masy ciała oraz wskaźników smukłości i BMI uczniów gimnazjów i szkół ponadgimnazjalnych [Score tables of body height, body mass and slenderness and BMI ratios of middle school and high school students]. AWF Press, Warszawa.

8. Frye A.J., E. Kamon (1981) Responses to dry heat of men and women with similar aerobic capacities. J. Appl. Physiol., 50: 65-70.

9. Ghods M., C. Corterier, K. Zindel, M. Kiene, K. Rudolf, M. Steen (2008) Hot air sauna burns. Burns, 34: 122-124.

10. Hannuksela M., S. Ellahham (2001) Benefits and risks of sauna bathing. Am. J. Med., 110: 118-126.

11. Havenith G. (1997) Individual Heat Stress Response. Ponsen en Looijen Press, Thesis. Nijmegen University, Vageningen.

12. Hawkins C. (1987) The sauna: killer or healer? Br. Med. J., 295: 1015-1016.
13. Hertig B.A. (1971) Human physiological responses to heat stress: males and females compared. J. Physiol. (Paris), 63: 270-273.

14. Kaupinen K., I. Vuori (1986) Man in the sauna. Ann. Clin. Res., 18: 173-185.

15. Kaupinen K. (1989) Sauna, shower, and ice water immersion. Physiological responses to brief exposures to heat, cool, and cold. Part III. Body temperatures." Arch. Med. Res., 48: 75-86.

16. Kauppinen K. (1997) Facts and fables about sauna. Ann. New York Acad. Sci., 813: 654-662.

17. Kenny G, O. Jay (2007) Evidence of a greater onset threshold for sweating in females following intense exercise. Eur. J. Appl. Physiol., 101: 487-493.

18. Kiss D., W. Popp, C. Wagner, H. Zwick, K. Sertl (1994) Effects of the sauna on diffusing capacity, pulmonary function and cardiac output in healthy subjects. Respiration, 61: 86-88.

19. Kohrt W.M., M.T. Malley, G.P. Dalsky, J.O. Holloszy (1992) Body composition of healthy sedentary and trained, young and older men and women. Med. Sci. Sport Exerc., 24(7): 832-837.

20. Koski A., V. Koljonen, J. Vuola (2005) Rhabdomyolysis caused by hot air sauna burn. Burns, 31: 776-779.

21. Kozłowski S., B. Saltin, (1964) Effect of sweat loss on body fluids. J. Appl. Physiol., 19(6): 1119-1124.

22. Kukkonen-Harjula K., K. Kauppinen, (2006) Health effects and risks of sauna bathing. Int. J. Cir. Health,. 65(3): 195-205.

23. Leppäluoto J., M. Tuominen, A. Väänänen, J. Karpakka, J. Vouri (1986) Some cardiovascular and metabolic effects of repeated sauna bathing. Acta Physiol. Scand., 128: 77-81.

24. Mack G.W., E.R. Nadel (1996) Body fluid balance during heat stress in humans. In: M.J. Fregly and C.M. Blatteis (eds.) Environmental physiology. Oxford University Press, New York, pp. 187-214.

25. Maughan R.J., S.M. Shirreffs, S.S. Ozgünen, G. Kurdak, M. Ersöz, S. Binnet, J. Dvorak (2010) Living, training and playing in the heat: challenges to the football player and strategies for coping with environmental extremes. Scand. J. Med. Sci. Sport., 20(3): 117-124.

26. Maughan R.J. (2003) Impact of mild dehydration on wellness and on exercise performance. Eur. J. Clin. Nutr., 57, Suppl. 2: 19-23.

27. Mehnert P., P. Bröde, B. Griefahn (2002) Gender-related difference in sweat loss and its impact on exposure limits to heat stress. Int. J. Ind. Ergon., 29: 343-351.

28. Montain S.J., E.F. Coyle (1992) Influence of graded dehydration on hyperthermia and cardiovascular drift during exercise. J. Appl.Physiol., 73: 1340-1350.

29. Montain S.J., W.A. Latzka, M.N. Sawka (1995) Control of thermoregulatory sweating is altered by hydration level and exercise intensity. J. Appl. Physiol., 79: 1434-1439. 
30. Nybo L., J. Thorbjørn, B. Nielsen, J. González-Alonso (2001) Effects of marked hyperthermia with and without dehydration on VO2 kinetics during intense exercise. J. Appl. Physiol., 90: 1057-1064.

31. Papp A. (2002) Sauna-related burns: a review of 154 cases treated in Kuopio University Hospital Burn Center 1994-2000. Burns, 28: 57-59.

32. Pilch W., Z. Szyguła T. Pałka T. Cisoń, Ż. Małgorzata (2006) Changes in chosen physiological parameters observed in women during sauna bath after overheating of the body due to excessive temperatures. Med. Sport. Practica, 7(4): 50-53.

33. Pilch W., Z. Szyguła M. Zychowska M. Gawinek (2003) The influence of sauna training on the hormonal system of young women. J. Hum. Kinet., 9: 19-30.

34. Rabiej M. (2012) Statystyka z programem Statistica [Statistics with program Statistica]. Gliwice: Helion S.A. Press.

35. Saltin B, D.L. Costill (1988) Fluid and electrolyte balance during prolonged exercise. In: E.S. Horton, R.J. Tenjung (eds.) Exercise nutrition and metabolism. Macmillan, New York, pp. 150-158.

36. Sawka M., F. Coyle (1999) Influence of body water and blood volume on thermoregulation and exercise performance in the heat. Exerc. Sport Sci. Rev., 27: 167-218.

37. Sawka M.N., S.J. Montain (2000) Fluid and electrolyte supplementation for exercise heat stress. Am. J. Clin. Nutr., 72: 564-572.

38. Sawka M.N., K.B. Pandolf (1990) Effects of body water loss on physiological function and exercise performance.” In: C.V. Gisolfi, D.R. Lamb (eds.) Perspectives in Exercise Science and Sports Medicine (Vol. 3), Fluid Homeostasis during Exercise. Benchmark Press, Carmel, Indiana, pp. 1-38.

39. Sawka M.N., A.J. Young R.P. Francesconi S.R. Muza K.B. Pandolf (1985) Thermoregulatory and blood responses during exercise at graded hypohydration levels. J. Appl. Physiol., 59: 1394-1401.
40. Schoffstall J.E., J.D. Branch, B.C. Leutholtz, D.P. Swain (2001) Effect of dehydration and rehydration on the onerepetition maximum bench press of weight-trained males. J. Strength Con. Res., 15: 102-108.

41. Shirreffs S.M., M.N. Sawka M. Stone (2006) Water and electrolyte needs for football training and match-play. J. Sport Sci., 24: 699-707.

42. Szyguła Z., A. Jurczak (1993) Effects of dehydration and overhydration on anaerobic power. Biol. Sport, 10: 159-165.

43. Thomas B., J. Cornish, B.H. Ward, L.C.A. Jacobs (2006) Bioimpedance: Is it a predictor of true water volume? Ann. New York Acad. Sci., 873(3): 89-93.

44. Watson P., I.D. Watson, R. Batt (1980) Total body water volumes for adult males and females estimated from simple anthropometric measurements. Am. J. Clin. Nutr., 33: 27-39.

45. Weinman K.P., Z. Siabochova, E.M. Berneuer, T. Morimoto, F. Sargent (1967) Reactions of men and women to repeated exposures to humid heat. J. Appl. Physiol., 22: 533-538.

46. Westerterp-Plantenga M., C.R.T. Verwegen, M.J.W. Ijedema, N.E.G. Wijckmans, W.H.M. Saris (1997) Acute Effects of Exercise or Sauna on Appetite in Obese and Nonobese Men. Physiol. Behav., 62(6): 1345-1354.

47. Ylikahri R., E. Heikkonen, A. Suokas (1988) The sauna and alcohol. Ann. Clin. Res., 20: 287-291.

\section{Received 17.10.2015 \\ Accepted 01.02.2016}

(C) University of Physical Education, Warsaw, Poland

\section{Acknowledgments}

The authors would like to thank the University of Warmia and Mazury in Olsztyn, Poland for financial support. 